\title{
Rheumatoid factor-negative juvenile idiopathic arthritis
}

INSERM

\section{Source}

INSERM. (1999). Orphanet: an online rare disease and orphan drug data base.

Rheumatoid factor-negative juvenile idiopathic arthritis. ORPHA:85408

Rheumatoid factor-negative polyarthritis is a term used to describe a group of poorly defined heterogenous conditions that incorporates forms of rheumatoid factor-negative polyarthritis and forms of oligoarticular arthritis that become extensive in less than 6 months after onset. 